\title{
Indirect effects of recreational fishing on behavior of the spiny lobster Panulirus argus
}

\author{
Darren M. Parsons*, David B. Eggleston
}

North Carolina State University, Department of Marine, Earth and Atmospheric Sciences, Raleigh, North Carolina 27695-8208, USA

\begin{abstract}
Sublethal disturbance may lead to behavioral modifications that have detrimental consequences for the individual. Sublethal disturbance is an indirect effect of fishing that has seldom been examined. In summer 2003, we conducted surveys on the Caribbean spiny lobster Panulirus argus in the Florida Keys, USA, before and after a 2 d mini-season exclusively for recreational sportdivers to assess the frequency of injured lobsters. We also conducted (1) a tethering experiment to assess the influence of disturbance and injury on predation-induced mortality, and (2) Y-maze laboratory experiments to assess the effect of injury and disturbance on the shelter choice of conspecifics. Injury surveys revealed an immediate increase (to $27.16 \%$ ) in the percentage of injured lobsters from pre- to post mini-season within patch reef habitats, but only a small increase in injured lobsters amongst patch head habitats. Tethering trials revealed that injured lobsters were more likely to succumb to predation than uninjured controls, while the shelter choice experiments demonstrated that the usual ability to attract conspecifics was altered by injury. Considering the ability of this fishery to unintentionally injure $>25 \%$ of the lobster population in patch reef habitats in just $2 \mathrm{~d}$, the potential population consequences to spiny lobsters must be examined.
\end{abstract}

KEY WORDS: Indirect behavioral disturbance $\cdot$ Sublethal injury · Unobserved mortality · Predation • Limb damage $\cdot$ Recreational fishing $\cdot$ Panulirus argus $\cdot$ Caribbean spiny lobster $\cdot$ Florida Keys

Resale or republication not permitted without written consent of the publisher

\section{INTRODUCTION}

When an animal encounters a predation threat it must make a choice between maintaining 'normal' activity patterns or changing activity to reduce the probability of predation. Both decisions have potentially detrimental consequences (Abrams 1993). Deciding to maintain 'normal' activity could be a fatal choice with direct implications, whereas a more conservative decision would reduce predation risk but could indirectly and negatively affect a host of functions including activity patterns, vigilance, sheltering behavior, social interactions, time spent feeding, growth and reproductive potential (see review by Lima 1998). These behavioral decisions are not without potentially long-term consequences for the individual, population or community.

Like natural predation events, marine fisheries can expose target species to direct effects through the removal of biomass, and indirect disturbance whereby surviving animals modify some aspect of their biology. The direct impact of biomass extraction is generally the focus of fisheries management; however, its indirect impacts and disturbances are largely ignored. Some indirect impacts of fishing that have been addressed include the capture of non-target species (Davis 2002), habitat destruction caused by contact fishing gears (Thrush et al. 2001), and trophic cascades resulting from reduced target species abundance (Babcock et al. 1999). Few studies, however, have addressed the potential for fishing practices to indirectly modify and disturb animal behavior. We do know that (1) fishes subjected to capture and release exhibit reduced growth and elevated mortality (Warner 1978, Loftus et al. 1988, Diggles \& Ernst 1997), (2) fish that escape through trawl nets have altered behaviors that may increase their risk of predation (Ryer et al. 2004), and (3) dredge fishery discards can lead to 
behavioral modification of scavengers (Veale et al. 2000). What is lacking and needed, is quantification of human disturbance events, the resulting behavioral modifications by target species and, if altered behaviors lead to increased mortality, the mechanisms underlying elevated mortality and population consequences of such delayed mortality.

Recreational spiny lobster fisheries provide a unique opportunity to quantify the effects of human disturbance on animal behavior and mortality because of the temporally intense, pulsed nature of this human disturbance (Eggleston et al. 2003), and because sportdivers visually locate and attack lobsters in their dens. Human disturbance of lobsters can result from either (1) an unsuccessful attack, or (2) a successful capture followed by release of a sub-legal lobster.

The Caribbean spiny lobster Panulirus argus supports important recreational and commercial fisheries throughout its range (Lipcius \& Eggleston 2000). P. argus is highly gregarious, aggregating in crevices and beneath sponges during the day (Herrnkind et al. 1975, Eggleston \& Lipcius 1992, Eggleston \& Dahlgren 2001), and foraging on gastropods, chitons and bivalves in nearby seagrass beds and hard bottom habitats at night (Cox et al. 1997). Ontogenetic habitat shifts occur when juveniles move from inshore macroalgal settlement habitats to back-reef crevice habitats, and finally to offshore reefs as adults (Davis \& Dodrill 1989). When spiny lobsters return to their dens from nocturnal foraging, or exhibit larger scale ontogenetic habitat shifts, they are guided by the olfactory cue of conspecifics, resulting in the aggregation of individuals in these shelters (Ratchford \& Eggleston 1998, 2000, Childress \& Herrnkind 2001). Commercial fishermen of the Florida Keys, exploit the gregarious nature of spiny lobsters by baiting traps with live juveniles (Hunt et al. 1986), whereas recreational sport-divers exploit the gregarious nature of lobsters by targeting dens with high densities of lobsters, and coercing them into hand-nets with 'tickle sticks' (Eggleston et al. 2003). Divers disturb lobsters within a den as they attempt to coerce the target individual out. In addition, sub-legal lobsters that are captured, measured, and released will also be disturbed and potentially injured. Therefore, the recreational fishery not only extracts $22 \%$ of the total lobster harvest in the Florida Keys each year (Hunt 2000), but probably exerts major indirect effects through disturbance and sublethal injury.

Approximately $50 \%$ of sub-legal and legal-sized spiny lobsters in Biscayne Bay, Florida, possessed injuries after the 1977 regular fishing season (compared to $31 \%$ injury immediately before that season opened in 1976; Davis 1981). These injuries reduced growth rates, and increased the probability of death of sub-legal lobsters before they recruited to the fishery (Davis 1981). Since Davis' (1981) study in the late 1970 s, the intensity of the recreational fishery in the Florida Keys has increased greatly. Most notably, during a $2 \mathrm{~d}$ mini-season exclusively for recreational sport-divers, which opens 1 wk prior to the opening of the regular lobster fishing season for commercial and recreational fishers during August to March (Eggleston \& Dahlgren 2001, Eggleston et al. 2003). For example, the abundance of post mini-season lobsters decreased by $55 \%$ in 1987 (Blonder et al. 1992), but decreased by 80 to $90 \%$ after the 2000 and 2002 miniseasons (Eggleston \& Dahlgren 2001, Eggleston et al. 2003). It seems reasonable to assume that the incidence of lobster injury and disturbance has increased accordingly, but this has remained untested.

In this study, we document the frequency of injured lobsters immediately before and after the $2 \mathrm{~d}$ miniseason for recreational sport-divers in the Florida Keys. We also investigated 2 potential consequences of disturbance and injury: (1) delayed predation-induced mortality, and (2) effects on gregarious sheltering behavior.

\section{MATERIALS AND METHODS}

Study sites. Lobster surveys and experiments were conducted within the Great White Heron National Wildlife Refuge on the NW side of the lower Florida Keys, Florida (Fig. 1). Within this region we surveyed 2 types of coral reef habitat: (1) continuous coral reefs and ledges, herein referred to as 'patch reefs', and (2) discrete aggregations of boulder coral located within shallow seagrass beds, herein referred to as 'patch heads' (see Eggleston et al. 2003 for description of coral patch reef and patch head habitats in this region).

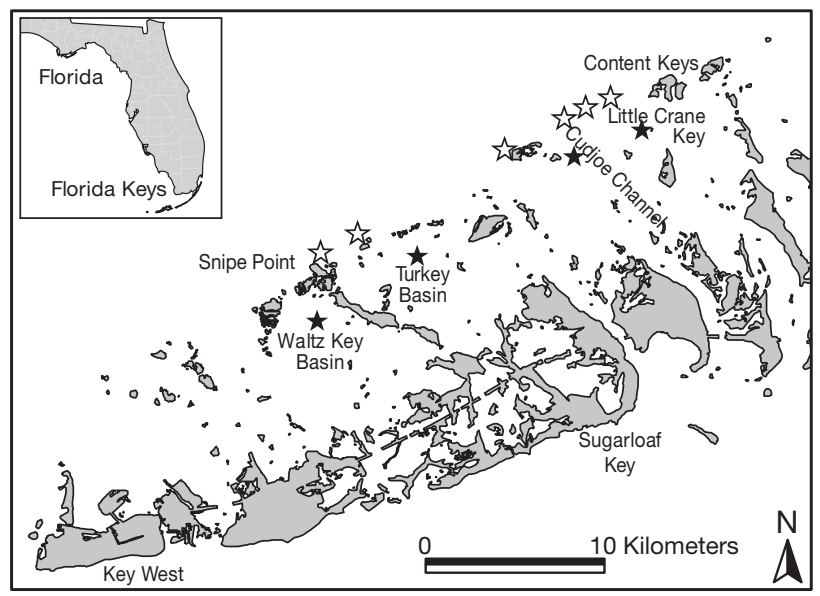

Fig. 1. Florida, USA (inset) and Florida Keys, showing patch reef ( $\star \star *)$ and patch head $(\star)$ study sites 
Patch reefs were located along a nearly continuous line running NE to SW and parallel to the lower Florida Keys (Fig. 1). Patch heads were located within discrete basins, such as Waltz Key Basin and Turkey Basin, along the edge of Cudjoe Channel, and in the area surrounding Little Crane Key (Fig. 1).

Sublethal lobster injury. SCUBA divers quantified the proportion and distribution of injured lobsters 4 to $6 \mathrm{~d}$ before and after the $2 \mathrm{~d}$ mini-season for sportdivers during July and August 2003. Injuries were defined as those lobsters missing $>50 \%$ of an antenna, missing legs, or with damage (i.e. crushed exoskeleton) to the abdomen, cephalothorax or supraorbital horns (Davis 1981). The size of injured lobsters was estimated visually (without capture) using a $50 \mathrm{~cm}$ long PVC pipe marked with $1 \mathrm{~cm}$ increments. All divers conducting these surveys had previously practiced estimating the size of plastic lobster models while diving, until estimates were accurate to within $1 \mathrm{~cm}$ carapace length (CL). When a lobster was partially obscured within a crevice, a tickle stick was used to gently coerce the lobster into view so that size could be estimated.

Patch reef survey sites were chosen by superimposing a $1 \mathrm{~km} \times 1 \mathrm{~km}$ grid over the continuous patch reef between Snipe Point and Content Keys (Fig. 1). From this grid, 6 cells were randomly selected. At each patch reef cell location, the research boat was anchored as close as possible to the middle of the grid cell using a differential GPS, whereupon 2 divers would survey areas in opposite directions from the boat. Each diver swam in the same direction before and after the $2 \mathrm{~d}$ mini-season. Divers used a $50 \mathrm{~cm}$ length of PVC pipe to estimate the width of the area searched, swimming along a nearly straight line away from the boat for $10 \mathrm{~min}$, then surfacing and visually estimating the distance traveled from the boat. Distances estimated in this manner are not significantly different from distances measured with a boat based differential GPS (Eggleston et al. 2003). In the current study, the average area searched for a given 10 min survey before the mini-season was greater $\left(380 \mathrm{~m}^{2}\right)$ than the average survey distance after the mini-season $\left(285 \mathrm{~m}^{2}\right)$, but these areas were not significantly different (paired $t$-test; $\mathrm{df}=11, t=1.96, \mathrm{p}$-value $>0.07)$. Therefore, lobster abundance was standardized to density (no. $\mathrm{m}^{-2}$ ), and the proportion of injured lobsters was compared between pre- and post mini-season.

Patch heads surveyed in this study were chosen from those measured in 2001 and 2002 for overall lobster loss from before to after the mini-season (Eggleston et al. 2003). Divers surveyed patch heads as described above, but searched the entire patch rather than using a transect approach (Eggleston et al. 2003). A total of 16 patch head clusters were surveyed from 4 separate locations: (1) Waltz Key Basin, (2) Turkey Basin, (3) Cudjoe Channel and (4) Little Crane Key (Fig. 1). The area of each patch head was calculated by measuring the radius of the coral patch head with a ruler and multiplying by $\pi r^{2}$. The response variable measured for coral patch heads was the proportion of injured lobsters within each survey site.

Effects of sublethal injury and disturbance on predation-induced mortality. Tethering experiments assessed the relative effects of disturbance and sublethal injury on predation-induced mortality of lobsters in the field. We hypothesized that injured lobsters would suffer higher predation-induced mortality than control lobsters because leaking body fluids would attract predators and potentially repulse conspecifics (Ratchford 1999), thereby reducing the benefits of group defense (Herrnkind et al. 2001). Each tether consisted of a $60 \mathrm{~cm}$ long monofilament line anchored to the substratum by a metal stake adjacent to a natural coral crevice. The other end of the tether was attached to a lobster by a cable-tie harness, which was secured around the cephalothorax between the second and third walking legs and fastened to the carapace using cyanoacrylate glue (Eggleston et al. 1990, Lipcius et al. 1998). The tether was long enough for the lobster to retreat into its shelter, but not so long that the lobster would became entangled. The minimum legal size of spiny lobsters that can be harvested in Florida is $76 \mathrm{~mm}$ CL. Thus, we chose spiny lobsters with an average CL of $74 \mathrm{~mm}$ to mimic sub-legal lobsters that are often captured, measured and released by sportdivers. At each of the 4 patch head locations, 3 lobsters were tethered to their own individual patch heads. Each lobster at a given location was randomly assigned to 1 of 3 treatments: (1) disturbed, whereby a lobster was prodded with a tickle stick for 1 min each day; (2) injured, whereby a lobster was initially injured by removing 1 antenna and the back 2 walking legs on one side of the cephalothorax; (3) control, with no disturbance or injury. The methods used in this study met established university, national and international guidelines for the ethical treatment of invertebrate animals.

If daily observations revealed that a given lobster was alive, the experiment was continued. If the lobster was absent and the tethering harness intact, the response was recorded as an escape. If part of the carapace remained attached to the tether or if the monofilament had been snapped, then the response was recorded as a predation event. Daily observations continued until the lobster had escaped, died, or until $5 \mathrm{~d}$ had elapsed. After $5 \mathrm{~d}$, it was assumed that starvation might confound results. When an experiment at a patch head was discontinued for one of the above reasons, another lobster would be tethered to the same 
patch head the next day and a treatment would be applied at random. In this way, 4 replicates were conducted within Cudjoe Channel, 3 at Turkey Basin, 2 around Little Crane Key and 1 at Waltz Key Basin, making a total of 10 replicates for each treatment over a $17 \mathrm{~d}$ period. To avoid human interference, these experiments were conducted when the fishery was closed. The response variable used was the probability of an individual within a treatment group surviving the full duration of the experiment $(5 \mathrm{~d})$. This was estimated with a survival function derived from the Kaplan-Meier procedure (Kaplan \& Meier 1958). Standard errors for this survival probability were calculated as described by Pollock et al. (1989). These survival probabilities were then compared between treatments using a 1-tailed normal distribution Z-test.

The second response variable observed in this experiment was the number of conspecifics co-occupying the patch head den with each tethered lobster. This number was recorded daily and adjusted to represent a percentage of the number of lobsters within that den when the experiment was initiated. We hypothesized that the average number of lobsters co-occupying a den with disturbed and injured lobsters would be significantly lower than the number of conspecifics occupying a den with control lobsters because the injured and disturbed lobsters would release body fluids or possibly stress hormones that could negate the effect of their natural attraction odor (Ratchford \& Eggleston 1998, Ratchford 1999). The daily percent initial occupancy by conspecifics was averaged for the duration of each tethering trial and analyzed with a 1-way ANOVA, with experimental treatment (injured, disturbed and control) as the class variable. The assumptions of ANOVA were met for these data (normality: Kolmogorov-Smirnov test, $\mathrm{p}>0.15$; homogeneity of variance: Levene's test, $\mathrm{p}>0.07$ ).

Effects of disturbance and injury on sheltering behavior. To assess how disturbance and injury modified normal sheltering behavior of Panulirus argus, a Y-maze, laboratory tank system was constructed (Fig. 2). We built 3 identical 235 l Y-maze, flowthrough seawater tanks $(1.9 \mathrm{~m} \times 0.61 \mathrm{~m} \times 0.28 \mathrm{~m})$ to allow 3 trials to be conducted simultaneously. Seawater was pumped into a $190 \mathrm{l}$ header tank, which fed six 38 l header tanks via adjustable valves. Seawater drained from pairs of these 381 header tanks into both sides of each Y-maze tank, after free falling $\sim 10 \mathrm{~cm}$ to ensure that no audible cues were transmitted directly from the header tank to the Y-maze (Ratchford \& Eggleston 1998). The only shelters available within the Y-maze tank were 2 concrete blocks placed on either side of the corners nearest the header tanks (Fig. 2). Seawater flowed through the Y-maze tanks, through a drainpipe, and then exited into a nearby canal. Water

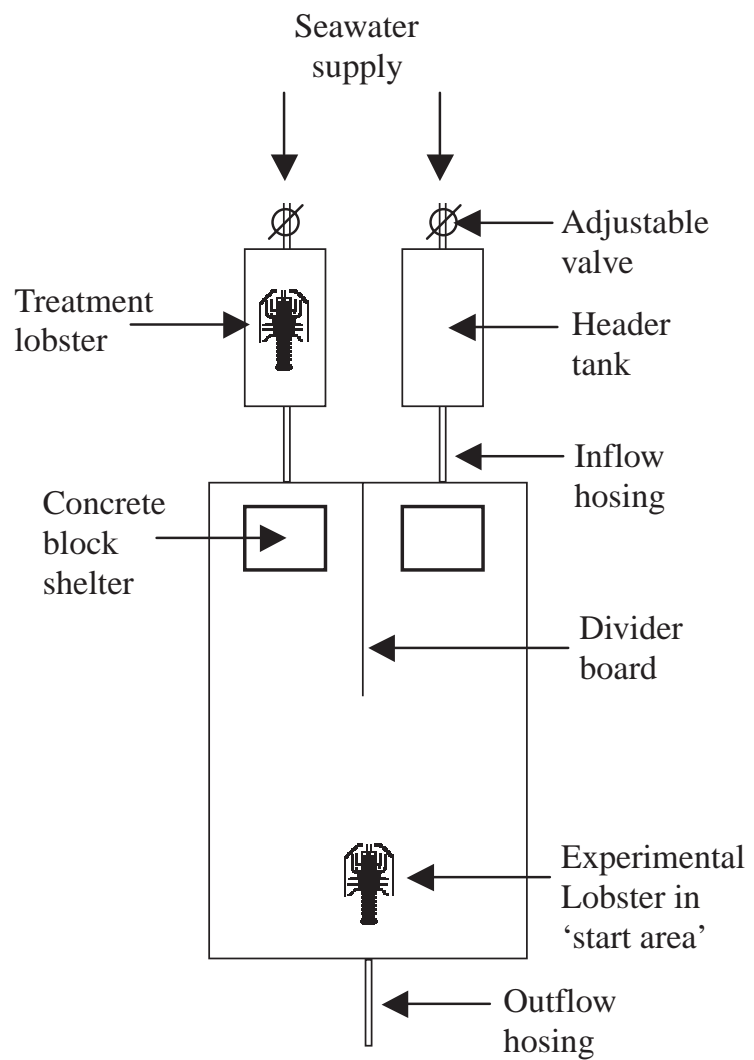

Fig. 2. Experimental Y-maze arena used to examine sheltering behaviour of Panulirus argus in response to injury and disturbance. Treatment (control, disturbance, or injury) was applied to lobster in header tank and shelter occupancy of experimental lobster was recorded in concrete block shelters

flow into each arm of the Y-maze was set at $\sim 1.51 \mathrm{~min}^{-1}$ (Ratchford \& Eggleston 1998). To check the directionality of flow in the Y-maze, fluorescein dye was added to 1 header tank and the flow observed. In all cases, the dye would flow into the start area, and not the other arm of the Y-maze, before flowing out through the drainpipe (Fig. 2).

Experimental trials were initiated in the evening ( 20:00 h) from July 29 to August 14, 2003. A trial began by randomly choosing one of the paired 381 header tanks to contain a lobster (hereafter referred to as the 'treatment lobster'). Another lobster (the 'experimental lobster') was then placed in the start area of each Y-maze tank (Fig. 2). Lobsters with an average CL of $75 \mathrm{~mm}$ were used in this experiment because they represented a sub-legal size that was expected to be most frequently handled and released by sportdivers, and were a close match to the average lobster size used in the field-tethering experiment. The Y-maze was then left undisturbed, with water constantly flowing until 04:30 h, after which one of each of the 3 treatments (disturbed, injured and control) was 
randomly assigned to 1 lobster in each of the header tanks. The disturbed treatment was conducted by prodding the lobster with a tickle stick for $\sim 1 \mathrm{~min}$; the injured treatment was conducted by breaking 1 antenna and the last 2 walking legs on one side of the lobster, while the control lobster was left undisturbed. This procedure was conducted under red light to ensure that all other lobsters remained undisturbed (Cummins et al. 1984).

The next morning before 08:00 $\mathrm{h}$, the shelter chosen by the experimental lobster was recorded. For each trial, the response was defined as either positive or negative. If the experimental lobster was sheltering in the concrete block downstream of the occupied header tank, then the experimental lobster's shelter choice was positively associated with a conspecific in the header tank. If the experimental lobster was sheltering downstream of the unoccupied header tank, the experimental lobster's shelter choice was negatively associated with a conspecific in the header tank. If the experimental lobster was not located within either concrete block shelter, then that individual trial was omitted from the results. A total of 11 disturbed, 13 injured and 10 control trials were successfully conducted. Data were analyzed by comparing the observed proportion of positive shelter choices for each treatment to the proportion expected by random choice (0.5). Differences between observed and expected shelter choices were assessed using 1-tailed binomial tests (Zar 1984). In addition, 1-tailed binomial unconditional p-values were calculated using 2 individual Fisher's exact tests to allow for comparison with the control treatment (Berger 1996). Where multiple comparisons were made, Type I error was controlled for by Bonferroni correction.

\section{RESULTS}

\section{Sublethal lobster injury}

During July 2003, both coral patch reef and patch head habitats contained an extremely low percentage of injured lobsters before the $2 \mathrm{~d}$ recreational miniseason ( 0 and $0.15 \%$, respectively). After the miniseason the percentage of injured lobsters had increased to $27.16 \%$ on patch reefs, and $3.77 \%$ on patch heads.

\section{Effects of sublethal injury and disturbance on predation-induced mortality}

The mean percent survival (Kaplan-Meier statistic) of tethered lobsters in coral patch heads prior to the mini-season declined with increasing intensity of the experimental treatment (Fig. 3). The only statistically

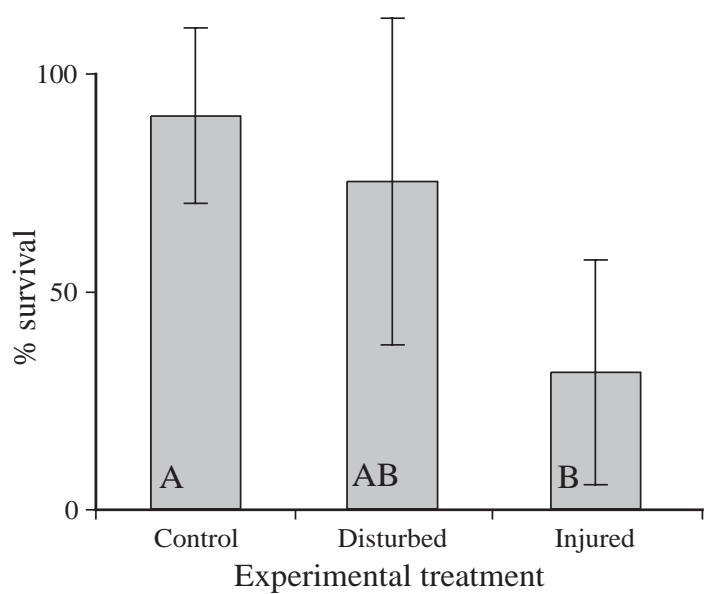

Fig. 3. Panulirus argus. Percent survival of lobsters tethered to coral patch heads as a function of disturbance (prodding with a tickle stick daily) or injury (loss of 1 antenna and 2 walking legs). Means $\pm \mathrm{SE}$ are shown; $\mathrm{n}=10$ for each treatment. Treatments with matching letters denote no significant difference upon pairwise comparison. See 'Results' for outcome of statistical tests

significant difference in percent survival, however, was between injured and control lobsters (1-tailed $Z$ test $\left._{(\alpha=0.05) ;} Z_{\text {obs }}=1.80, Z_{\text {crit }}=1.65\right)$. The percent survival of disturbed lobsters was not significantly different than survival of injured (1-tailed $Z$ test $_{(\alpha=0.05)} Z_{\mathrm{obs}}=$ 0.97, $\left.Z_{\text {crit }}=1.65\right)$ or control (1-tailed $Z$ test $_{(\alpha=0.05) ;} Z_{\text {obs }}=$ $0.35, Z_{\text {crit }}=1.65$ ) lobsters.

While applying the daily disturbance and injury treatments to the tethered lobsters, the number of coresident Panulirus argus was recorded to determine any potential avoidance behavior or decreased attraction by untethered conspecifics residing within coral patch heads. There was a decrease in the daily proportion of lobsters co-resident with control and injured lobsters, but not with disturbed lobsters (Fig. 4). Significantly more co-resident lobsters remained with disturbed than injured lobsters (1-way ANOVA; $d f=2$, $F=3.87, \mathrm{p}<0.04)$. However, neither the injured nor disturbed treatments were significantly different from the control (Tukey's multiple comparison test).

\section{Effects of disturbance and injury on sheltering behavior}

The strength of attraction by Panulirus argus to conspecific odors decreased as the intensity of the treatment increased (Fig. 5). For example, lobsters chose shelter receiving water from an undisturbed conspecific $80 \%$ of the time, which was significantly greater than random (binomial test; $\mathrm{n}=10, \mathrm{p}=0.04$ ). The percent of lobsters attracted to conspecifics was not different than random in the disturbed $\left(55 \%\right.$ : binomial test ${ }_{i}$ 


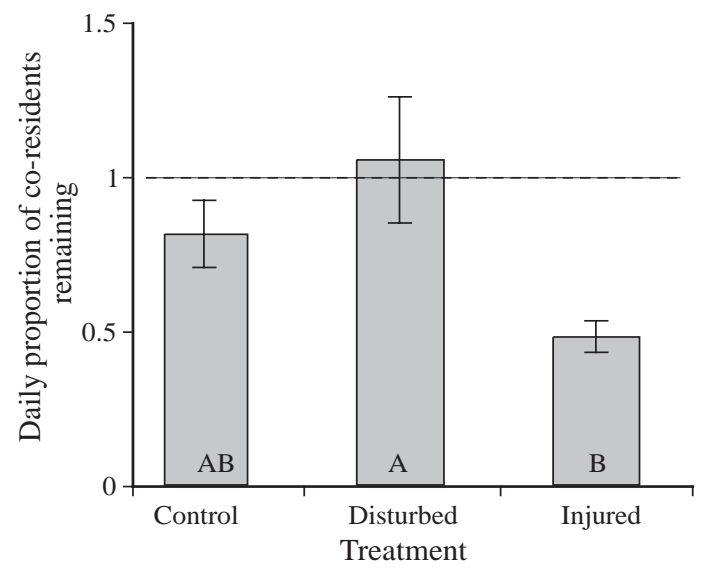

Fig. 4. Panulirus argus. Mean $( \pm \mathrm{SE})$ daily proportion of original number of co-resident lobsters remaining in coral patch heads during tethering experiments. This was determined by counting initial number of co-resident lobsters within the same coral patch head as the tethered lobster and daily recounting them. Dashed line: null hypothesis of no change in number of coresident lobsters over time. Treatments with matching letters denote no significant difference upon pairwise comparison

$\mathrm{n}=11, \mathrm{p}=0.23)$ and injured (38\%: binomial test; $\mathrm{n}=$ $13, \mathrm{p}=0.16)$ treatments. The percent of lobsters attracted to control lobsters was significantly higher than the percent of lobsters attracted to injured lobsters at the 0.05 level of significance and provided some evidence of a significant difference at the 0.025 level, after accounting for multiple comparisons (Fisher's exact test; unconditional p-value $=0.03$ ). The control versus disturbed $(p$-value $=0.13)$ comparison revealed no significant difference in the percentage of lobsters attracted (Fig. 5).

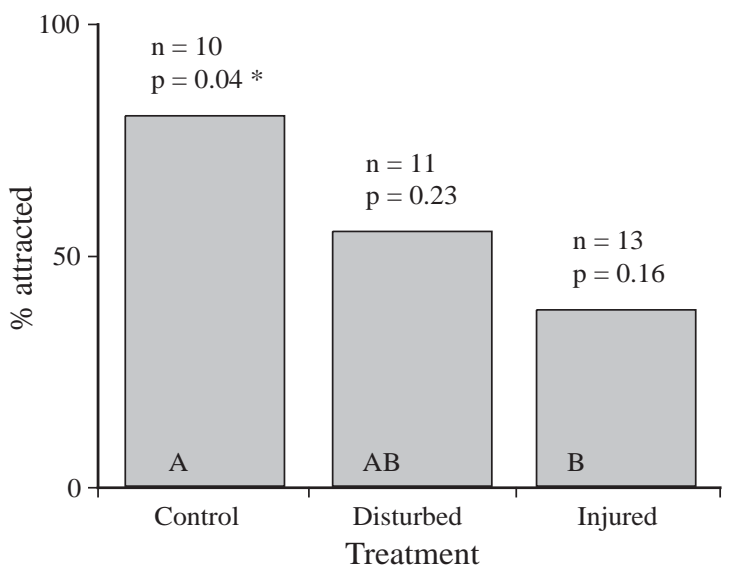

Fig. 5. Panulirus argus. Results of Y-maze laboratory experiment testing effects of disturbance and injury on attractiveness of experimental lobsters to conspecifics. p-values were based on a 1-tailed binomial test (Zar 1984), where null probability of choosing a shelter with conspecific odor $=0.5 ; *$ : significant at $\alpha=0.05$. Treatments without matching letters denote borderline significant difference at $\alpha=0.025$ upon pairwise comparison using multiple Fisher's exact tests

\section{DISCUSSION}

This study illustrates that sublethal disturbances by recreational sport-divers can increase the frequency of injured lobsters, alter shelter choice behavior, and increase predation-induced mortality of injured lobsters. Examples of behavioral disturbance in the marine environment are rare, although tourism activities like dolphin-watching are known to alter marine mammal behavior (Constantine et al. 2004). The current study is one of the first (as far as we are aware) to demonstrate that recreational fishing disturbance may increase mortality of the target species through a modification of prey behavior. In commercial fisheries, behavioral impairment caused by escape through trawl cod-ends may elevate mortality of juvenile walleye pollock Theragra chalcogramma exposed to the lingcod predator Ophiodon elongatus (Ryer 2002). In terrestrial systems, redistribution and increased nocturnal activity of white-tailed deer Odocoileus virginianus exposed to hunters has been hypothesized to increase predation by the Florida panther Felis concolor coryi (Kilgo et al. 1998). The current study has shown that sublethal disturbances can have detrimental consequences for individuals, and we recommend quantification of similar disturbance events in other fisheries.

\section{Sublethal lobster injury}

The percentage of injured lobsters increased from 0 to $27 \%$ in coral patch reefs during the sport-diver mini-season. While previous studies have indicated a high percentage of injury resulting from the cumulative and often long-term effects of recreational and commercial fishing (an increase from 31 to $50 \%$ over a 7 mo fishing season; Davis 1981), the current study has shown that a substantial increase in the frequency of injury can occur over only $2 \mathrm{~d}$. Since injuries to fishery target species can reduce survival (Ryer et al. 2004), the frequency at which they occur and the subsequent increase in mortality rate should be incorporated into population and fishery stock assessment models. Alternatively, on coral patch heads we did not observe a large increase in the percentage of injured lobsters from pre- to post mini-season. This was opposite to the pattern of injury frequency we expected given that sport-diver fishing effort can be 10-fold greater on coral patch heads than on coral patch reefs (Eggleston et al. 2003).

It is unclear why the percentage of injured lobsters was low in coral patch head habitats compared to coral patch reefs. Physical differences between patch heads and patch reefs may result in easier capture of lobster at patch heads, thereby reducing the chance of injur- 
ing lobsters. For example, patch heads are generally surrounded by sand and seagrass. Lobsters that escape an initial capture attempt by divers will typically tailflip into another den in the same patch head, or onto the surrounding sand and seagrass. Once a lobster is in the seagrass it is easily captured by placing a hand-net behind it and coercing it into the net with a tickle stick (D. M. Parsons pers. obs.). Thus, the attack success by divers on patch heads may be higher than on patch reefs, resulting in fewer remaining injured lobsters. Another explanation might involve the dispersion of injured lobsters away from disturbed dens and toward alternative, potentially suboptimal shelters. These hypotheses remain to be tested.

\section{Effects of sublethal injury and disturbance on predation-induced mortality}

The increased mortality of injured lobsters in the tethering study, and the elevated frequency of injury after the mini-season, suggest that lobster injury increases overall mortality rates on lobsters. While estimates of mortality may be inflated due to experimental artefacts common to all tethering experiments (Peterson \& Black 1994), it is the relative differences between treatments that are of interest here. We did not observe any differences in artefacts between treatments, such as a higher probability of lobsters tangling in the tether for some treatments.

The higher predation rate on injured versus control lobsters in the field could be due to 3 non-mutually exclusive mechanisms. (1) When an injury occurs flesh is exposed, releasing a mixture of organic compounds. These compounds include amino acids, which are known chemical attractants of foraging predators (Zimmer et al. 1999). Therefore, predators with a good olfactory sense, such as sharks (Hamlett 1999), could follow this odor trail and more easily locate their prey. (2) The defensive capacity of a lobster may be reduced by injury. If legs are removed it may restrict a lobster's mobility and therefore ability to escape. Removal of the antenna, which are used to whip potential predators (Herrnkind et al. 2001), may limit a lobster's ability to successfully fend off attackers. (3) Injured lobsters may lose the benefits of group defense (Herrnkind et al. 2001) when co-resident lobsters abandon the den. This third mechanism was probably not important in determining patterns of predator-induced mortality in this study, since co-resident lobsters abandoned dens containing tethered lobsters that were exposed to both control and injury treatments. At time-scales greater than the duration of this study, an additional mechanism for higher mortality of injured lobsters would be increased energetic costs associated with injury (Juanes
\& Smith 1995). Increased energetic demand may cause an animal to take greater risks to obtain food and reduce its ability to escape predators (Sinclair \& Arcese 1995), further elevating predation.

\section{Effects of disturbance and injury on sheltering behavior}

The results from our Y-maze experiments indicated that lobsters are attracted to dens containing conspecifics, as has been previously observed (Ratchford \& Eggleston 1998). This strong tendency for lobsters to seek shelter emitting the odor of conspecifics appeared to be reduced when the treatment lobster was injured. Moreover, reduced attractiveness by conspecifics toward injured lobsters could alter the ecological relationship between gregariousness, predation risk and shelter choice observed in Panulirus argus (Eggleston \& Lipcius 1992), and reduced social interaction could lessen the benefits of group defense (Herrnkind et al. 2001).

Lobsters find suitable shelter faster when there are conspecifics within a shelter than when they are absent (Childress \& Herrnkind 2001). Therefore, when high numbers of injured lobsters exist in a den, the cues lobsters use to find dens may be reduced. This reduction in the 'guide effect' (Childress \& Herrnkind 2001) may alter local patterns of habitat use, even for lobsters that are not disturbed or injured. For example, undisturbed lobsters may be stranded in soft sediment habitats in the absence of correct cues from uninjured lobsters (Childress \& Herrnkind 2001). Moreover, lowered success in finding suitable daytime shelter may expose lobsters to a relatively high risk of predation mortality. There are 2 potential mechanisms explaining the reduced attraction behavior observed in our Y-maze choice experiments. Either production of the normal attractive odor (Ratchford \& Eggleston 1998) may be reduced or cease when lobsters are disturbed or injured, or disturbance and injury may initiate the release of a disturbance odor. Results of a similar experiment also indicated that disturbance may promote the release of an odor that alters the sheltering behavior of conspecifics (Ratchford 1999). If such a disturbance odor exists, it could serve as a pheromone that is unintentionally released under stressful conditions. It would provide no benefit to the message sender, but broadcast information about predation risk (Chivers \& Smith 1998). Since the disturbed and injured treatments in the current study did not produce significant avoidance, it is likely that if a disturbance odor exists, it does not operate to the exclusion of the attraction odor. This would indicate that either the production of the attraction odor was reduced or terminated, or that the attraction and disturbance odors were competing with one another. 


\section{FINAL REMARKS}

Reduced growth rates of sub-legal lobsters caused by injury may prolong the time they spend in smaller size classes, resulting in an additional $22 \%$ of sub-legal lobsters succumbing to natural predation before they enter the fishery (Davis 1981). Our study suggests that injured lobsters will also be exposed to a higher daily rate of predation, which could further decrease the proportion of individuals eventually recruiting to the fishery. Spiny lobsters also appear to alter their sheltering behavior in the presence of injured conspecifics, which may affect survival. The population-level and fishery implications of these indirect disturbances remain unknown, but some level of unobserved mortality is likely to exist. Detrimental effects of human disturbance have been demonstrated at the population level amongst various terrestrial species (e.g. mule deer, Yarmoloy et al. 1988; caribou, Harrington \& Veitch 1992; pink footed geese, Madsen 1994), but less frequently in marine fisheries where the indirect effects of human disturbance and the direct effects of fishing itself may be difficult to separate. Matthews (2001), however, estimated that exposure and confinement of juvenile Panulirus argus used as attractants in traps reduces recruitment to the fishery by 0.646 million individuals annually. If the population-level consequences of the human disturbance events described in the current study can also be quantified, management attempts to reduce the frequency of avoidable injuries to sub-legal lobsters and/or account for this unobserved mortality may prove beneficial.

With respect to the potential impact of indirect effects in other recreational lobster fisheries, recreational catch data are rare and there have been no investigations, that we are aware of, addressing the indirect effects of recreational fishermen. In South Africa, Western Australia and New Zealand, annual recreational catches of spiny lobsters are $\sim 379,630$ and $300 \mathrm{t}$, respectively (Cockcroft \& Mackenzie 1997, Melville-Smith et al. 2001, K. J. Sullivan unpubl. data). This represents $25,4.8$ and $\sim 10 \%$ of the total annual landings in the respective countries. In contrast, the Floridian recreational fishery lands $225 \mathrm{t}$ in the first $2 \mathrm{~d}$, and accounts for $\sim 40 \%$ of the total annual landings (Sharp et al. 2005). In all but one of these fisheries, there have been recent increases in the percentage of the total catch taken by recreational fishermen: an increase of $\sim 10 \%$ between 1993 and 2001 in Florida (Sharp et al. 2005), 18\% between 1991 and 1995 in South Africa (Cockcroft \& Mackenzie 1997), and 3\% between 1986 and 1998 in Western Australia (MelvilleSmith et al. 2001). Whether the increasing proportion of landings by the recreational fishery will correspondingly increase the frequency of injured lobsters is unclear. Regardless of the percentage of catch obtained by recreational fishermen, spiny lobster fisheries throughout the world may have large unobserved mortalities associated with commercial diving and trapping. Commercial fishers in the Florida Keys also have a high potential to contribute indirect effects to the lobster population, since sub-legal lobsters are used as attractants and traps are set for long periods (up to a month) without escape gaps (Matthews 2001). In other countries, traps usually have escape gaps and soak for $\sim 1$ d (Phillips et al. 1994, D. M. Parsons pers. obs.). The differences in fishing methods suggest that indirect effects are probably most prevalent in the Floridian fishery, but may still be of concern to other spiny lobster fisheries. The frequency of indirect impacts on a given fishery will depend on the relative proportion of different capture methods within a fishery, and the potential for sublethal injuries posed by each method. While indirect impacts should be assessed in all fisheries, of particular interest is how the magnitude of indirect impacts will change as some fisheries become dominated by recreational effort (Coleman et al. 2004).

Acknowledgements. Thanks to G. Bell, M. Darcy and G. Plaia for assistance with field work; M. Childress, J. Hightower, $\mathrm{S}$. Thrush, T. Wollcot and 2 anonymous reviewers for comments on the manuscript; and K. Pollock, and N. Tolimieri for statistical assistance. We thank J. Sobel of The Oceans Conservancy for facilitating the research funding and his enthusiastic administration of this project; and A. Gude of the US Fish \& Wildlife Service for logistical support. Funding for this project was provided by a Challenge Cost-Share Agreement between The Oceans Conservancy and the US Fish \& Wildlife Service for Contracts 1448-40181-99-6 and 144840181-00-6143, as well as the Fund for Sustainable Fisheries, North Carolina State University. This research was conducted with a research and education permit granted by the Florida Keys National Marine Sanctuary Program (FKNMS-2002-061).

\section{LITERATURE CITED}

Abrams PA (1993) Why predation rate should not be proportional to predator density. Ecology 74:726-733

Babcock RC, Kelly S, Shears NT, Walker JW, Willis TJ (1999) Changes in community structure in temperate marine reserves. Mar Ecol Prog Ser 189:125-134

Berger RL (1996) More powerful tests from confidence interval $p$ values. Am Stat 50:314-318

Blonder BI, Hunt JH, Forcucci D, Lyons WG (1992) Effects of recreational and commercial fishing on spiny lobster abundance at Looe Key National Marine Sanctuary. In: Waugh GT, Godwin MH, Kau SM (eds) Proc 41st Gulf Carib Fish Inst 41:487-491

Childress MJ, Herrnkind WF (2001) The guide effect influence on the gregariousness of juvenile Caribbean spiny lobsters. Anim Behav 62:465-472

Chivers DP, Smith RJF (1998) Chemical alarm signalling in aquatic predator-prey systems: a review and prospectus. Ecoscience 5:338-352

Cockcroft AC, Mackenzie AJ (1997) The recreational fishery 
for west coast rock lobster Jasus lalandii in South Africa. S Afr J Mar Sci 18:75-84

Coleman FC, Figueira WF, Ueland JS, Crowder LB (2004) The impact of United States recreational fisheries on marine fish populations. Science 305:1958-1960

Constantine R, Brunton DH, Dennis T (2004) Dolphin-watching tour boats change bottlenose dolphin (Tursiops truncatus) behaviour. Biol Conserv 117:299-307

Cox C, Hunt JH, Lyons WG, Davis GE (1997) Nocturnal foraging of the Caribbean spiny lobster (Panulirus argus) on offshore reefs of Florida, USA. Mar Freshw Res 48: 671-679

Cummins DR, Chen DM, Goldsmith TH (1984) Spectral sensitivity of the spiny lobster, Panulirus argus. Biol Bull (Woods Hole) 166:269-276

Davis GE (1981) Effects of injuries on spiny lobster, Panulirus argus, and implications for fishery management. Fish Bull (Seattle) 78:979-984

Davis GE, Dodrill JW (1989) Recreation fishery and population dynamics of spiny lobsters, Panulirus argus in Florida Bay, Everglades National Park, 1977-1980. Bull Mar Sci 44:78-88

Davis MW (2002) Key principles for understanding fish bycatch discard mortality. Can J Fish Aquat Sci 59:1834-1843

Diggles BK, Ernst I (1997) Hooking mortality of two species of shallow-water reef fish caught by recreational angling methods. Mar Freshw Res 48:479-483

Eggleston DB, Dahlgren CP (2001) Distribution and abundance of Caribbean spiny lobsters in the Key West National Wildlife refuge: relationship to habitat features and impact of an intensive recreational fishery. Mar Freshw Res 52:1567-1576

Eggleston DB, Lipcius RN (1992) Shelter selection by spiny lobster under variable predation risk, social conditions, and shelter size. Ecology 73:992-1011

Eggleston DB, Lipcius RN, Miller DL, Coba-Cetina L (1990) Shelter scaling regulates survival of juvenile Caribbean spiny lobster Panulirus argus. Mar Ecol Prog Ser 62:79-88

Eggleston DB, Johnson EG, Kellison GT, Nadeau DA (2003) Intense removal and non-saturating functional responses by recreational divers on spiny lobster prey. Mar Ecol Prog Ser 257:197-207

Hamlett WC (1999) Sharks, skates, and rays: the biology of elasmobranch fishes, Vol I. Johns Hopkins University Press, Baltimore, MD

Harrington FH, Veitch AM (1992) Calving success of woodland caribou exposed to low-level jet fighter overflights. Arctic 45:213-218

Herrnkind WF, Vanderwalker J, Barr L (1975) Population dynamics, ecology and behavior of spiny lobsters off St. Johns, U.S. V.I. Habitation, patterns of movement, and general behavior. Sci Bull Nat Hist Mus Los Angel Cty 20: $31-45$

Herrnkind WF, Childress MJ, Lavalli KL (2001) Cooperative defence and other benefits among exposed spiny lobsters: inferences from group size and behaviour. Mar Freshw Res 52:1113-1124

Hunt JH (2000) Status of the fishery for Panulirus argus in Florida. In: Phillips BF, Kittaka J (eds) Spiny lobsters: fisheries and culture. Blackwell Science, Oxford, p 189-199

Hunt JH, Lyons WG, Kennedy FS Jr (1986) Effects of exposure and confinement on spiny lobsters, Panulirus argus, used as attractants in the Florida trap fishery. Fish Bull (Seattle) 84:69-76

Juanes F, Smith LD (1995) The ecological consequences of limb damage and loss in decapod crustaceans: a review and prospectus. J Exp Mar Biol Ecol 193:197-223

Kaplan EL, Meier P (1958) Nonparametric estimation from incomplete observations. J Am Stat Assoc 53:457-481

Kilgo JC, Labisky RF, Fritzen DE (1998) Influences of hunting on the behavior of white-tailed deer: implications for conservation of the Florida panther. Conserv Ecol 12: 1359-1364

Lima SL (1998) Stress and decision making under the risk of predation: recent developments from behavioral reproductive and ecological perspectives. Adv Stud Behav 27: 215-290

Lipcius RN, Eggleston DB (2000) Introduction: ecology and fishery biology of spiny lobsters. In: Phillips BF, Cobb JS, Kittaka J (eds) Spiny lobster management. Blackwell Science, Oxford

Lipcius RN, Eggleston DB, Miller DL, Luhrs TC (1998) The habitat-survival function for Caribbean spiny lobster: an inverted size effect and non-linearity in mixed algal and seagrass habitats. Mar Freshw Res 49:807-816

Loftus AJ, Taylor WW, Keller M (1988) An evaluation of lake trout (Salvelnius namaycacush) hooking mortality in the upper great lakes. Can J Fish Aquat Sci 45:1473-1479

Madsen J (1994) Impacts of disturbance on migratory waterfowl. Ibis 137:567-574

Matthews TR (2001) Trap-induced mortality of the spiny lobster, Panulirus argus, in Florida, USA. Mar Freshw Res 52:1509-1516

Melville-Smith R, Anderton SM, Caputi N (2001) Predicting the recreational western rock lobster (Panulirus cygnus) in Western Australia. Mar Freshw Res 52:1527-1534

Peterson CH, Black R (1994) An experimentalist's challenge: when artefacts of intervention interact with treatments. Mar Ecol Prog Ser 111:289-297

Phillips BF, Cobb JS, Kittaka J (1994) Spiny lobster management. Blackwell Scientific, Cambridge, MA

Pollock KH, Winterstein SR, Bunck CM, Curtis PD (1989) Survival analysis in telemetry studies: the staggered entry design. J Wildl Manag 53:7-15

Ratchford SG (1999) The influence of chemical Communication on shelter selection, shelter sharing, and aggregation among spiny lobsters, Panulirus argus. PhD dissertation North Carolina State University, Raleigh, NC

Ratchford SG, Eggleston DB (1998) Size- and scale-dependent chemical attraction contribute to an ontogenetic shift in sociality. Anim Behav 56:1027-1034

Ratchford SG, Eggleston DB (2000) Temporal shift in the presence of a chemical cue contributes to a diel shift in sociality. Anim Behav 59:793-799

Ryer CH (2002) Trawl stress and escapee vulnerability to predation in juvenile walleye pollock: Is there an unobserved bycatch of behaviorally impaired escapees? Mar Ecol Prog Ser 232:269-279

Ryer CH, Ottmar ML, Sturm EA (2004) Behavioral impairment after escape from trawl codends may not be limited to fragile fish species. Fish Res 66:261-269

Sharp WC, Bertelsen RD, Leeworthy VR (2005) Long-term trends in the recreational lobster fishery of Florida, United States: landings, effort, and implications for management. NZ J Mar Freshw Res 39:733-747

Sinclair ARE, Arcese P (1995) Population consequences of predation-sensitive foraging: the Serengeti wildebeest. Ecology 76:882-891

Thrush SF, Hewitt JE, Funnell GA, Cummings VJ, Ellis J, Schultz D, Talley D, Norkko A (2001) Fishing disturbance and marine biodiversity: the role of habitat structure in simple soft-sediment systems. Mar Ecol Prog Ser 223: $277-286$ 
Veale LO, Hill AS, Brand AR (2000) An in situ study of predator aggregations on scallop (Pecten maximus (L.)) dredge discards using a static time-lapse camera system. J Exp Mar Biol Ecol 255:111-229

Warner K (1978) Hooking mortality of lake dwelling landlocked Atlantic salmon, Salmo salar. Trans Am Fish Soc 107:518-522

Yarmoloy C, Bayer M, Geist V (1988) Behavior responses and

Editorial responsibility: Otto Kinne (Editor-in-Chief), Oldendorf/Luhe, Germany reproduction of mule deer, Odocoileus hemionus, does following experimental harassment with an all-terrain vehicle. Can Field-Nat 102:425-429

Zar JH (1984) Biostatistical analysis, 2nd edn. Prentice-Hall, Englewood Cliffs, NJ

Zimmer RK, Commins JE, Kenneth AB (1999) Regulatory effects of environmental chemical signals on search behavior and foraging success. Ecology 80:1432-1446

Submitted: June 22, 2004; Accepted: May 24, 2005

Proofs received from author(s): October 18, 2005 